\title{
Frozen chicken import, domestic chicken production, and real exchange rates in Ghana: A trivariate causality analysis
}

\author{
Prince Fosu \\ School of Analytics, Finance and Economics, \\ Southern Illinois University Carbondale, \\ Carbondale, IL, USA \\ prince.fosu@siu.edu \\ ORCID 0000-0001-8536-8311
}

\begin{abstract}
Ghana currently spends over USD 300 million annually on frozen chicken import. As a result, policy makers, researchers, and politicians are worried about the potential impact of escalating imports on the domestic poultry industry and on the Ghanaian cedi. The principal objective of this study is to establish the existence of a joint causal relationship between frozen chicken import, domestic chicken production, and real exchange rate in Ghana using the Breitung and Candelon (2006) frequency domain causality test, Granger causality test, and Vector Autoregressive (VAR) estimation technique. The frequency domain causality test revealed a unidirectional causality running from domestic chicken production to frozen chicken import, and from frozen chicken import to real exchange rate in all time periods. However, in the short run, a bidirectional causality was found between domestic chicken production and real exchange rate. The outcome of this paper has important implications for global food policy and trade policy. The results suggest that domestic chicken production affects real exchange rate via frozen chicken import. Thus, policies that increase domestic chicken production could decrease frozen chicken import and hence stabilize the real exchange rate in Ghana.
\end{abstract}

Keywords: frozen chicken import, domestic chicken production, real exchange rates, trivariate causality, Ghana.

JEL Classification: F14, Q17, Q18

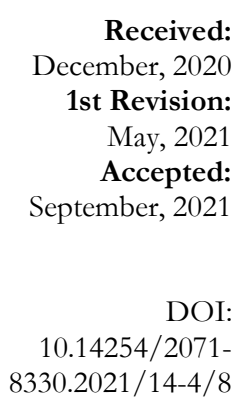

$8330.2021 / 14-4 / 8$

\section{INTRODUCTION}

Ghana is the third major importer of frozen chicken in Africa after Angola and South Africa (USDA ERS, 2020, see Graph 2). Currently Ghana imports over 240,000 MT of chicken, beef, and other meat to make up for its meat deficit costing over US $\$ 375$ million annually (Ministry of Food and Agriculture, 2019). Evidence also shows that the country spends about $\$ 300$ million annually to import frozen chicken (Ghana 
Agricultural and Rural Development Journalists Association, 2015). National demand for poultry meat alone in Ghana is projected to be 400,000 MT with domestic production of just about 57,871MT (Ministry of Food and Agriculture, 2019). Poultry meat consumed in Ghana include chickens, guinea fowls, ducks, turkeys and ostrich, although chicken is generally consumed (USDA, FAS, 2008). In Ghana, broiler meat imports constitute over 80 percent of the total meat imports (Ministry of Food and Agriculture, 2019). Although, chicken production has increased, there has also been an increase in consumption in Ghana which far outweighs the supply (Amanor-Boadu et al., 2015).

The United States accounts for over 40 percent of chicken meat import by Ghana, while the EU and Brazil account for about 25 percent each (USDA, 2017). In 2015, about 42 percent of poultry meat consumed in Ghana was from domestic production, with the remaining 58 percent being imported from the U.S. and the European Union (Ministry of Food and Agriculture, 2015). The increased chicken meat import by the Ghanaian economy has made it very difficult for local producers to expand their business and has also contributed to the depreciation of Ghanaian cedi against the US dollar and other major foreign currencies (Business Day Ghana, 2015). As a result, in the year 2014, the Government of Ghana was called upon to ban the importation of poultry products so as to save the local industry and to stabilize the Ghanaian cedi which has seen massive depreciation over the past years (Business Day Ghana, 2015). Kusi et at., (2015) indicated that poultry feed alone accounts for about 70 percent of the poultry farmer's production cost in Ghana. In West Africa, and in particular Ghana, maize is the main poultry feed ingredient and also a staple food for many households (The Poultry Site, 2016). Also, Kusi et al (2017) indicated that maize accounts for about 60 percent of poultry feed in Ghana. Increased demand for maize for feed and household consumption makes it not only relatively expensive but also scarce.

Although Ghana is endowed with a lot of resources, has conducive environment and the capacity to produce poultry that will be sufficient for local consumption and exports, yet factors such as low government spending in the agricultural sector, high cost of chicken feeds, high interest rates, and high cost of energy among others have been responsible for the inadequate poultry production in the country. Because of these issues, domestic demand for chicken meat far exceed local production (see Graph 1). Recently, the Government of Ghana has adopted policies such as the "rearing for food and job" and also has given subsidies to attract more people into broilers production (Ministry of Food and Agriculture, 2019). The subsidies include providing farmers with 1000-2000-day old chicks, vaccines, and feed for the first two weeks of production (Ministry of Food and Agriculture, 2019). The rational for adopting these policies is to increase domestic poultry production, ensure food security, increase local consumption, job creation, raise incomes, and increase exports.

Rapid population growth, high income growth, low price of frozen chicken, rapid growth in restaurants, hotels and fast food sector among others have led to increase domestic consumption of poultry meat and therefore increased demand for imported poultry products over the past years (USDA, FAS 2017, Kusi et al., 2017). Although frozen chicken import has boosted household food consumption and animal protein intake among low income earners in Ghana who cannot afford expensive meat such as local chicken meat, beef, and dry fish among others, it has also contributed to depreciation the Ghana cedi, high unemployment, health risk, and dumping. While previous studies have analyzed the poultry sector in Ghana, majority of these studies have investigated the structure and the sectoral analysis of the poultry industry using survey and descriptive analysis (Aning, 2006; Andam et at., 2017; Amanor-Boadu et al., 2015; Banson et at., 2015; Kusi et at., 2015; Sumberg et al., 2017). In recent times, the continuous import of frozen chicken into the Ghanaian economy has generated a lot of concerns and public debates among farmers, politicians, researchers, and policy makers etc. due to the impact of increased frozen chicken import on domestic poultry industry and on the depreciation of the cedi. Yet, empirical studies that examine the linkage between frozen chicken import, domestic chicken production, and real exchange rate have been neglected for Ghana. 
Therefore, the focus of the study is to establish whether there is a joint causal interaction between frozen chicken import, domestic chicken production, and real exchange rates in Ghana using the VAR framework. The study contributes to empirical literature because it is the first empirical study to examine the tri-variate causality among frozen chicken import, domestic chicken production, and real exchange rate using frequency-domain causality test. The findings of the study also have significant implications for global food policy and trade policy. There rest of the paper is organized as follows: section 1 presents literature review, section 2 presents the methodological approach and section 3 presents the result and discussions. Conclusions are given in section 4.

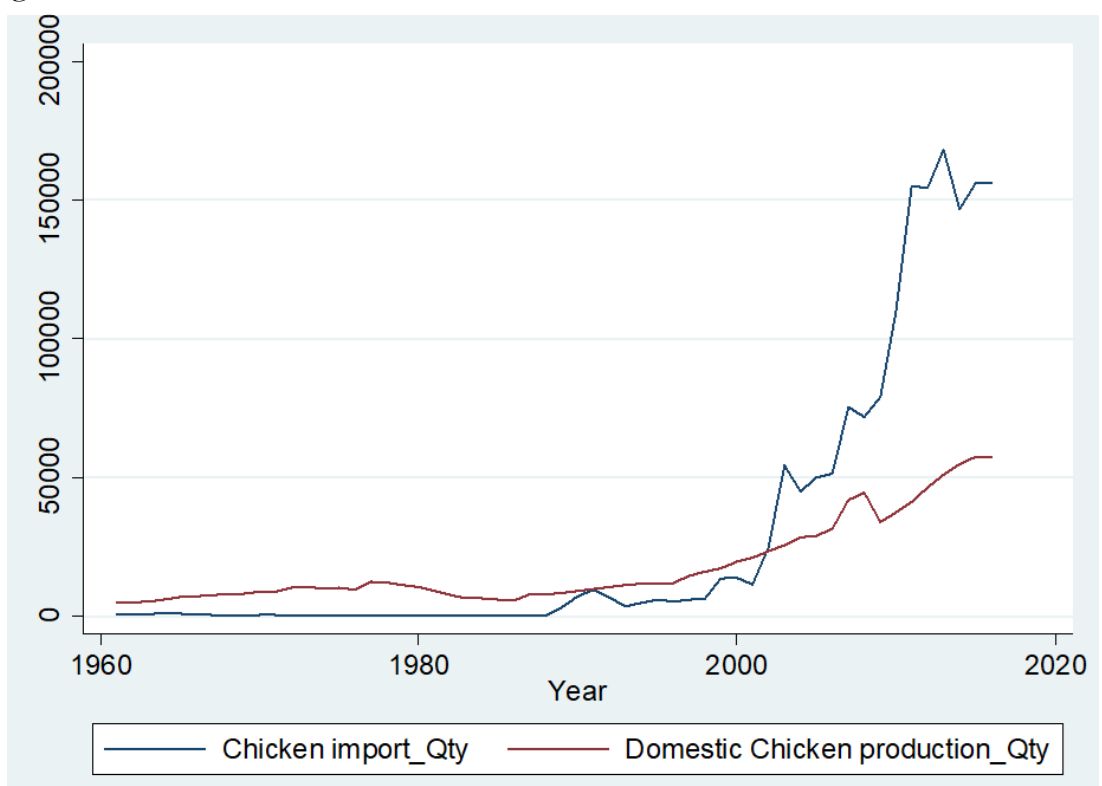

Graph 1. Ghana's poultry imports (MT) and poultry production (MT) (1964-2016) Source: FAOSAT (2017).

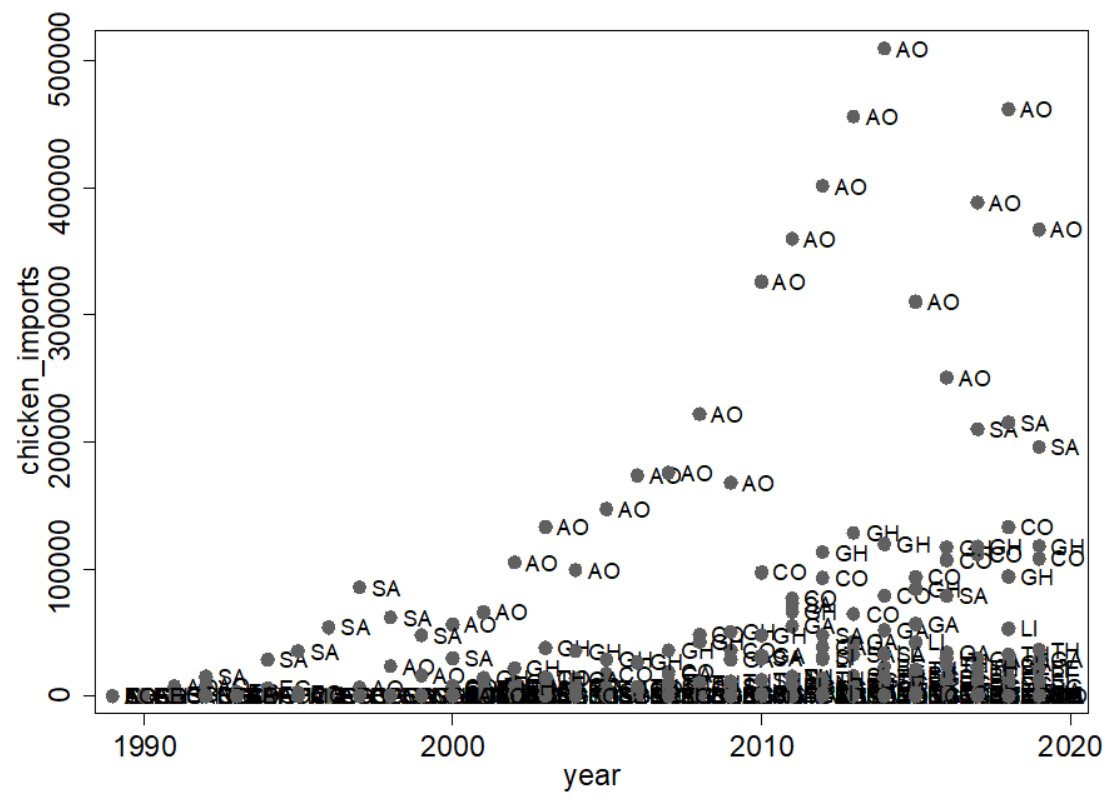

Graph 2. Poultry Imports by African countries from the US (MT) (1989-2019) Source: USDA, ERS (2020) 


\section{LITERATURE REVIEW}

Previous studies that have analyzed the causal interactions between frozen chicken import, chicken production, and real exchange rates for Ghana are scarce. As a result, I reviewed the literature on poultry industry in general. Employing the hedonic price analysis, Al-Hassan et al., (2014) to investigate the dressed chicken in Ghana. Specifically, the study used fifty consumers from Kumasi and time series data from 2001 to 2010 to establish the preference between local and imported chicken and to analyze price trends using a growth model. The findings from the study revealed that consumers are willing to pay premiums for imported, non fatty, and tender attributes of chicken. Also, their found that prices of local chicken are about 57 percent higher however, the volume of the imported chicken had a faster growth rate.

More so, in their study, Andam et at., (2017) used the partial equilibrium analysis and examined of the poultry feed sector situation in Ghana. Their study specifically focused on the feed milling industry which serve as the connection between feed and poultry. The results showed that availability and price of maize feed played largely determined the profitability and growth role of the poultry industry. Also, it was found that poultry meat replacing imports with domestic production would be nearly impossible in the short term.

In addition, the work of Woolverton and Frimpong (2013) used a conditional logistic regression model and examined the consumer demand for domestic and imported broilers meat in urban Ghana. That is, the study investigated if consumers in Greater Accra are willing to pay for non-price attributes in poultry. The study finds that purchase decisions are based on price and non-price attributes such as convenience, freshness and origin of the products. The study suggests an opportunity to market domestic chicken based on both price and price attributes and increased investment in domestic poultry industry is required.

Also, in their work, Banson et al., (2015) investigated the challenges facing the poultry sector in Ghana. The revealed that feed cost account for about $70 \%$ of the total cost of broilers production. Also, feed utilization efficiency was found to be critical for growth rates of broilers. Furthermore, the study indicated the constraint facing the poultry industry in Ghana is the lack of protection on the infant poultry industry in Ghana. Other major constraint facing the public sector as indicated in the study are high feed cost, high chicken mortality as well as high cost of electricity. The study suggested the need for the government to intervene in the poultry market to alleviate these challenges.

In a similar study, Donkor et al., (2013) used a sample size of 350 respondents and analyzed their choice of imported and domestic produced chicken in Kumasi Metropolis. The study found that price and quality of chicken meat are the major factors that influence the purchasing decision of the consumers in Kumasi Metropolis. The concluded that there is the need to ensure effective competitive price for locally produced chicken by providing adequate and readily funding for farmers. Also, packaging of locally produced chicken should be enhanced to compete with the international markets.

Furthermore, Kusi et al., (2015) used secondary data to examine the challenges and prospects of the commercial poultry industry in Ghana. Their paper suggested that Government of Ghana to increase taxes on importation of frozen chicken, increase SME financing, establish more training schools for poultry famers, and encourage consumption of local poultry meats. Their paper also encourages entrepreneurs to resolve both financial and managerial issues affecting the poultry sector in Ghana. It can be observed that almost all the studies reviewed seem to employ survey and descriptive statistics to analyze the poultry sector and consumer choice demand in Ghana. That is, no studies so far have empirically examined the joint causal relationship or dynamic interaction that exist between chicken imports, domestic chicken production, and real exchange rate in Ghana using the VAR framework. 


\section{METHODOLOGY}

The objective of this study is to establish whether there is a joint causal interaction between frozen chicken import, domestic chicken production, and real exchange rates in Ghana. The study employed the vector autoregressive (VAR) estimation technique. The VAR estimation has the ability to capture dynamic interactions among the variables and address endogeneity bias that exist in the structural model. However, conclusions drawn from the VAR model may be sensitive to model specification. As a result, before carrying out the VAR estimation, pre-estimation tests such as the units root tests and granger causality tests were performed.

The unit root test is conducted to examine the stationarity properties of the variables so as to come up with statistically reliable estimates and also to avoid spurious regression. Spurious regression occurs when time series regression results reveal statistically significant results, have high R-square yet have no meaningful relationship (Gujarati, 2004). To test for stationarity, the study employed the Augmented Dickey-Fuller (ADF) test and the Phillips-Perron (PP) test. Assuming the study found similar results for these tests, the $\mathrm{ADF}$ test will be used to check for the stationarity property.

In addition, the granger causality test developed by Granger (1969) and Sims (1969) was employed. The test was conducted to determine whether one variable is useful in forcasting another variable (Granger, 1969; Granger, 1986; Sims, 1972; Stock \& Watson, 2001). The test is premise on the assumption that the future cannot cause the past, rather, it is the past that causes the presents or the future. Also, it assumes that the cause contains a unique information about the effect not available elsewhere (Gujarity, 2004). That is, a time series $X_{t}$ is said to granger cause $Y_{t}$ if the lagged values of $X_{t}$ provide significant information about the future value of $Y_{t}$ (Granger 1969). The mathematical representation of the Granger caussality test is built on linear regression modeling of stochastic processes (Granger 1969). The mathematical formulation of granger causality is specified below:

$$
Y_{t}=\varnothing+\varsigma t+\eta_{1} Y_{t-1}+\cdots+\eta_{p} Y_{t-p}+\mu_{1} X_{t-1}+\cdots+\mu_{p} X_{t-p}+\epsilon_{t}
$$

The Granger causality test besically test the hypothesis that $\mu_{1}=\mu_{2}=\cdots=\mu_{P}=0$. Rejecting the null hypothesis implies that the time series $X_{t}$ granger cause $Y_{t}$. Furthermore, in the trivariate regression analysis, joint causality was suggested when the coefficients of frozen chicken import, chicken production, and real exchange rates were statistically significantly different from zero.

In addition to the conventional granger causality test, I employed the frequency domain or spectral test of causality developed by Breitung and Candelon (2006). The Breitung and Candelon (2006) frequency domain test was built on Granger (1969), Geweke (1982), and Hosoya (1991). The frequency domain analysis essentially decompose the variability in a time series into short tern, intermediate, and long run. Decomposing the time periods helps to determine the relatively more important frequencies that contribute to fluctuations in the variable (Tastan, 2015). The null hypothesis of the frequency domain test is that $y_{t}$ does not Granger cause $x_{t}$ conditional on $z_{t}$ at (i.e. Ho: $\mathrm{M}_{y \rightarrow x / z}(w)=0$ ) frequency w. Following Ciner (2011), I chose the frequency (w) value: $\mathrm{w}=0.5$ (short term), $\mathrm{w}=1.5$ (intermediate), and $\mathrm{w}=2.5$ (long term).

To determine the optimal lag to be used in the VAR model a lag length selection criteria was performed. The lag length selection criteria helps to avoid multicollinearity and specification error. The optimal lag length k, based on the Akaike Information Criterion (AIC) was used to estimate the VAR model (Gujarati, 2004). The estimated VAR model comprised of three variables, frozen chicken import, chicken production, and real exchange rate and was applied to the data set in the form of a trivariate model. The mathematical representation of the trivariate VAR model are specified below: 


$$
\begin{aligned}
& D C P_{t}=\delta_{1}+\sum_{i=1}^{k} \xi_{1 i} D C P_{t-i}+\sum_{i=1}^{k} \gamma_{1 i} F C I_{t-i}+\sum_{i=1}^{k} \tau_{1 i} R E R_{t-I}+\varepsilon_{1 t} \\
& F C I_{t}=\delta_{2}+\sum_{i=1}^{k} \xi_{2 i} D C P_{t-i}+\sum_{i=1}^{k} \gamma_{2 i} F C I_{t-i}+\sum_{i=1}^{k} \tau_{2 i} R E R_{t-I}+\varepsilon_{2 t} \\
& R E R_{t}=\delta_{3}+\sum_{i=1}^{k} \xi_{3 i} D C P_{t-i}+\sum_{i=1}^{k} \gamma_{3 i} F C I_{t-i}+\sum_{i=1}^{k} \tau_{3 i} R E R_{t-I}+\varepsilon_{3 t}
\end{aligned}
$$

Where DCP indicates domestic chicken production (MT), FCI indicates frozen chicken import (MT), RER indicates real exchange rate calculated as RER $=\left(E R * C P I \_G H / C P U \_U S\right), E R$ is nominal exchange rate (LCU per US\$, period average), CPI_GH is conumer price index $(2010=100)$ in Ghana, CPI_US is conumer price index $(2010=100)$ in the foreign country (i.e. US), $\delta$ s are the intercept parameter, $\xi, \gamma$, and $\tau$ are unknown cofficients to be estimated, $\varepsilon$ s are the error terms, $\mathrm{i}=1 \ldots \mathrm{k}$ is the number of lags, and $\mathrm{k}$ is the optimal lag length. The study solely relied on secondary data covering the period of 1964 to 2016. Data on domestic chicken production and chicken import were gleaned from the Food and Agricultural Organization (FAO), nominal exchange rate, and consumer index data were obtained from the World Development Indicators (WDI). Real exchange rate data was calculated by the author.

It is assumed that increase in chicken import can lead to a reduction in domestic chicken production. On the contrary, increase domestic production of chicken can also lead to reduction in frozen chicken import. More so, exchange rate fluctuations can influence both chicken import and chicken production while changes in frozen chicken import and domestic chicken production can also cause real exchange rate to fluctuate.

Assuming all the variables are integrated of the same order and have cointegration (i.e. long run relationship), the vector error correction model (VECM) will be carried out. On the contrary, if the series have different order of integeration and have no cointegration then the VAR estimation will be performed.

Furthermore, the Variance Decomposition analysis (VDC) was performed to examine the relative importance of each random shock by showing the forcast error variance of each endogeneous variable. The paper also conducted the Impulse Response Function (IRF) to observe the reaction of the dynamic model in response to some external shocks.

\section{EMPIRICAL RESULTS AND DISCUSSION}

Table 1 presents the descriptive statistics of the variables. Frozen chicken import within the period average 30,175.36 metric tons, while domestic chicken production average 18,636.15 metric tons. Also, the average Ghana cedi/US $\$$ exchange rate is equivalent to 0.572 . The coefficients of skewness are positive for frozen chicken import (1.697), domestic chicken production (1.323), and real exchange rate (3.397) indicating that frozen chicken import, domestic chicken production, and real exchange rate are positively skewed.

Furthermore, the results of the augmented Dickey Fuller (ADF) and the Phillip-Perron (PP) indicate that all variables are non-stationary at levels but when they were differenced once, they all became stationary (see Table 2). The results suggest that frozen chicken import, domestic chicken production, and real exchange rate all have unit roots. Thus, all variables have their order of integration to be order one. 
Summary statistics

\begin{tabular}{|l|c|c|c|}
\hline & FCI & DCP & RER \\
\hline Mean & 30175.36 & 18636.15 & 0.572390 \\
\hline Median & 3497.000 & 11250.00 & 0.001176 \\
\hline Maximum & 168235.0 & 57276.00 & 7.341883 \\
\hline Minimum & 19.00000 & 5760.000 & $6.58 \mathrm{E}-09$ \\
\hline Std. Dev. & 51660.72 & 15210.32 & 1.428062 \\
\hline Skewness & 1.697429 & 1.322959 & 3.396621 \\
\hline Kurtosis & 4.430841 & 3.444992 & 14.55958 \\
\hline Jarque-Bera & 29.97231 & 15.89756 & 396.9966 \\
\hline Probability & 0.000000 & 0.000353 & 0.000000 \\
\hline Sum & 1599294. & 987716.0 & 30.33669 \\
\hline Sum Sq. Dev. & $1.39 \mathrm{E}+11$ & $1.20 \mathrm{E}+10$ & 106.0468 \\
\hline Observations & 53 & 53 & 53 \\
\hline
\end{tabular}

Source: World Bank and FAO, Software: EViews SV 11.

Table 2

Unit roots test

\begin{tabular}{|l|c|c|c|c|c|}
\hline & ADF (Intercept) & & $\begin{array}{c}\text { PP } \\
\text { (Intercept) }\end{array}$ & & \\
\hline & T-Stat & t-Statistic & T-Stat & t-Statistic & Order of \\
\hline Variable & Levels & First Diff & Levels & First Diff & integration \\
\hline FCI & -0.307 & -6.062 & -0.168 & -6.682 & $\mathrm{I}(1)$ \\
\hline DCP & 0.563 & -5.874 & 0.338 & -5.9 & $\mathrm{I}(1)$ \\
\hline RER & 10.325 & 10.699 & 32.431 & 32.432 & $\mathrm{I}(1)$ \\
\hline
\end{tabular}

Source: World Bank and FAO, Software: EViews SV 11.

In addition, the correlation analysis was carried out to examine the possible connections that exist between the variables. The results of the correlation analysis are shown in Table 3 . The test shows a strong positive correlation between frozen chicken import and domestic chicken production and also between domestic chicken production and real exchange rate in Ghana.

Table 3

Correlation analysis

\begin{tabular}{|l|c|c|c|}
\hline & FCI & DCP & RER \\
\hline FCI & 1 & 0.871 & 0.575 \\
\hline DCP & 0.871 & 1 & 0.703 \\
\hline RER & 0.575 & 0.703 & 1 \\
\hline
\end{tabular}

Source: World Bank and FAO, Software: EViews SV 11.

The lag order selection criterion was performed to determine the optimal lag to be used for the estimation (see Table 4). Based on the lag length selection criteria, the appropriate lag chosen for the cointegration test and the VAR estimation was one. 
Table 4

Lag order selection criteria

\begin{tabular}{|l|c|c|c|c|c|c|}
\hline Lag & LogL & LR & FPE & AIC & SC & HQ \\
\hline 0 & -206.027 & NA & 1.018 & 8.531 & 8.648 & 8.576 \\
\hline 1 & 4.178 & 386.092 & $0.000^{*}$ & $0.319^{*}$ & $0.783^{*}$ & $0.495^{*}$ \\
\hline 2 & 6.233 & 3.523 & 0.000 & 0.602 & 1.414 & 0.910 \\
\hline 3 & 19.896 & $21.749^{*}$ & 0.000 & 0.412 & 1.571 & 0.852 \\
\hline 4 & 23.681 & 5.561 & 0.000 & 0.625 & 2.131 & 1.197 \\
\hline
\end{tabular}

* indicates lag order selected by the criterion

Source: World Bank and FAO, Software: EViews SV 11.

Before performing the VAR estimation, the Johansen test of cointegration was performed. The Johansen cointegration test results are presented in Tables 5 and 6 . At the optimal lag 1, both the trace and maximum eigenvalue test of cointegration suggest evidence of no cointegration. Therefore, the study estimated the VAR model.

Table 5

Unrestricted cointegration rank test (Trace)

\begin{tabular}{|l|c|c|c|c|}
\hline Hypothesized & & Trace & 0.05 & \\
\hline No. of CE(s) & Eigenvalue & Statistic & Critical Value & Prob. $^{* *}$ \\
\hline None & 0.202 & 21.167 & 29.797 & 0.347 \\
\hline At most 1 & 0.167 & 9.681 & 15.495 & 0.306 \\
\hline At most 2 & 0.007 & 0.349 & 3.841 & 0.555 \\
\hline
\end{tabular}

Source: World Bank and FAO, Software: EViews SV 11.

Table 6

Unrestricted cointegration rank test (maximum eigenvalue)

\begin{tabular}{|l|c|c|c|c|}
\hline Hypothesized & & Max-Eigen & 0.05 & \\
\hline No. of CE(s) & Eigenvalue & Statistic & Critical Value & Prob.** $^{* *}$ \\
\hline None & 0.202 & 11.487 & 21.132 & 0.599 \\
\hline At most 1 & 0.167 & 9.332 & 14.264 & 0.260 \\
\hline At most 2 & 0.007 & 0.349 & 3.841 & 0.555 \\
\hline
\end{tabular}

Source: World Bank and FAO, Software: EViews SV 11.

Furthermore, the pairwise granger causality test was performed to determine the causal relationship that exist among the variables. The results of the pairwise granger causality test is shown in Table 7. The results indicate a bidirectional causal relationship between frozen chicken import and domestic chicken production and a unidirectional causality running from domestic chicken production and frozen chicken import to real exchange rate. 
Pairwise Granger Causality Test

\begin{tabular}{|l|l|c|c|}
\hline Null Hypothesis: & \multicolumn{1}{l|}{ Obs } & F-Statistic & Prob. \\
\hline FCI does not Granger Cause DCP & 51 & $3.623^{* *}$ & 0.035 \\
\hline DCP does not Granger Cause FCI & 51 & $4.762^{* *}$ & 0.013 \\
\hline RER does not Granger Cause DCP & \multicolumn{1}{|l|}{1.368} & 0.265 \\
\hline DCP does not Granger Cause RER & 51 & $2.772^{*}$ & 0.073 \\
\hline RER does not Granger Cause FCI & \multicolumn{2}{|l|}{0.157} & 0.855 \\
\hline FCI does not Granger Cause RER & $7.712^{* * *}$ & 0.001 \\
\hline
\end{tabular}

Note: $*, * *, * *$ indicates $1 \%, 5 \%$, and 10\% significance level respectively.

Source: World Bank and FAO, Software: EViews SV 11.

In addition, to determine the direction of causality among frozen chicken import, domestic chicken production, and real exchange rate in the short run, intermediate, and long run periods, I performed the Breitung and Candelon (2006) frequency-domain causality test (see Table 8). In the short run, the test revealed a unidirectional causality running from domestic chicken production to frozen chicken import and from frozen chicken import to real exchange rate, but a directional causality was found between domestic chicken production and real exchange rate. Similarly, in the intermediate and long run, the test showed a unidirectional causality from domestic chicken production to frozen chicken import and from frozen chicken import to real exchange rate. The results suggest that, domestic chicken production affects real exchange rate via frozen chicken import in all time periods but in the short run, real exchange rate also affect domestic chicken production. The graphical presentations of the frequency-domain causality tests are shown in Appendix B.

Table 8

Frequency-domain causality test

\begin{tabular}{|c|c|c|c|c|c|}
\hline & & & SR & IP & LR \\
\hline $\begin{array}{c}\text { Causality } \\
\text { Outcome }\end{array}$ & Period & Lag & $w=0.5$ & $w=1.5$ & $w=2.5$ \\
\hline DCP $\rightarrow$ FCI & $1964-2016$ & 3 & $37.163^{* * *}$ & $33.840^{* * *}$ & $36.908^{* * *}$ \\
& & & $(0.000)$ & $(0.000)$ & $(0.000)$ \\
\hline FCI $\rightarrow$ DCP & $1964-2016$ & 3 & 0.112 & 2.588 & 3.605 \\
& & & $(0.946)$ & $(0.274)$ & $(0.165)$ \\
\hline DCP $\rightarrow$ RER & $1964-2016$ & 3 & $12.889^{* * *}$ & $11.442^{* * *}$ & $10.744^{* * *}$ \\
& & & $(0.002)$ & $(0.003)$ & $(0.005)$ \\
\hline RER $\rightarrow$ DCP & $1964-2016$ & 3 & $6.029^{* *}$ & 2.951 & 2.191 \\
& & & 0.049 & $(0.229)$ & $(0.334)$ \\
\hline FCI $\rightarrow$ RER & $1964-2016$ & 3 & $21.123^{* * *}$ & $9.279 * * *$ & $16.253^{* * *}$ \\
& & & $(0.000)$ & $(0.009)$ & $(0.000)$ \\
\hline RER $\rightarrow$ FCI & $1964-2016$ & 3 & 0.4778 & 0.463 & 0.464 \\
& & & $(0.788)$ & $(0.793)$ & 0.793 \\
\hline
\end{tabular}

Note: $* * *, * * *$ indicates $1 \%, 5 \%$, and 10\% significance level respectively. $\mathrm{SR}=$ short run, $\mathrm{IP}=$ intermediate period, LR=long run, w=frequency. Values in bracket are P-Value for the Wald statistic. Source: World Bank and FAO, Software: Stata 14.2. 
The results from the variance decomposition (VDC) are presented in Table 9, 10, and 11.

The VDC measures the proportion of the forecast error variance for a variable that can explained by exogenous shocks. The VDC results indicated that there was no variable that is entirely self-explained or exogenous because all variables fail to explain all the $100 \%$ of their shocks or innovations at 10 period. From Table 9, 10, and 11, the forecast error variance for frozen chicken import, domestic chicken production, and real exchange rate were $82.90 \%, 51.25 \%$, and $98.59 \%$ respectively.

Table 9 presents the VDC for frozen chicken import. At period 1, it can be observed that frozen chicken import is exogenous suggesting that frozen chicken import is entirely influenced by its own innovations. However, overtime, frozen chicken import is influenced by both real exchange rate and domestic chicken production. Also, it can be observed that the impact of real exchange rate on frozen chicken import continue to increase overtime however, the impact of domestic chicken production on frozen chicken import fluctuates overtime.

Specifically, about $10.5 \%$ and $6.5 \%$ of the variation in frozen chicken import in period 10 , was explained by disturbances in real exchange rates and domestic chicken production respectively. This result confirms the granger causality test which shows that domestic chicken production granger causes frozen chicken import, however, contradicts the results of no causality from real exchange rate to frozen chicken import.

Table 9

Variance decomposition of frozen chicken import

\begin{tabular}{|c|c|c|c|c|}
\hline Period & S.E. & FCI & DCP & RER \\
\hline 1 & 0.715 & 100.000 & 0.000 & 0.000 \\
\hline 2 & 0.969 & 99.736 & 0.240 & 0.024 \\
\hline 3 & 1.149 & 99.157 & 0.741 & 0.103 \\
\hline 4 & 1.292 & 98.284 & 1.439 & 0.613 \\
\hline 5 & 1.416 & 97.112 & 2.275 & 1.212 \\
\hline 6 & 1.531 & 95.595 & 3.192 & 2.232 \\
\hline 7 & 1.643 & 93.632 & 4.137 & 3.904 \\
\hline 8 & 1.759 & 91.043 & 5.053 & 6.550 \\
\hline 9 & 1.885 & 87.575 & 5.875 & 10.568 \\
\hline
\end{tabular}

Source: EViews SV 11. Note: S.E. refers to standard error

Table 10 also presents the VDC for domestic chicken production. Table 10 shows that about 46.5\% of the shocks in domestic chicken production is attributed to frozen chicken import in period 10, while about $2.1 \%$ of shocks in domestic chicken production is explained by real exchange rate. The results suggest that frozen chicken import largely determine domestic chicken production in Ghana. While frozen chicken import and real exchange rate continue to increase overtime, domestic chicken production also continue to decrease overtime. The result support the causality test in Table 7 which shows a bidirectional causality between frozen chicken import and domestic chicken production. 
Variance decomposition of domestic chicken production

\begin{tabular}{|c|c|c|c|c|}
\hline Period & S.E. & FCI & DCP & RER \\
\hline 1 & 0.101 & 0.383 & 99.617 & 0.000 \\
\hline 2 & 0.139 & 3.942 & 96.057 & 0.001 \\
\hline 3 & 0.169 & 9.440 & 90.554 & 0.006 \\
\hline 4 & 0.196 & 15.840 & 84.136 & 0.024 \\
\hline 5 & 0.222 & 22.364 & 77.567 & 0.070 \\
\hline 6 & 0.248 & 28.539 & 71.295 & 0.167 \\
\hline 7 & 0.273 & 34.124 & 65.525 & 0.351 \\
\hline 8 & 0.300 & 39.017 & 60.302 & 1.242 \\
\hline 9 & 0.327 & 43.181 & 55.577 & 2.167 \\
\hline 10 & 0.355 & 46.586 & 51.247 & \\
\hline
\end{tabular}

Source: World Bank and FAO, Software: EViews SV 11. Note: S.E. refers to standard error

Table 11 presents the VDC results for real exchange rate. The results indicate that overtime, the impact of frozen chicken import on real exchange rate continue to increase while the impact of domestic chicken production on real exchange rate also continue to decrease overtime. In addition, frozen chicken import and domestic chicken production explain about $1.4 \%$ of the total variations in real exchange rate. The results are consistent with the results from both pairwise granger causality test and frequency-domain causality test.

Table 11

Variance decomposition of real exchange rate

\begin{tabular}{|c|c|c|c|c|}
\hline Period & S.E. & FCI & DCP & RER \\
\hline 1 & 0.191 & 0.430 & 0.841 & 98.729 \\
\hline 2 & 0.315 & 0.645 & 0.642 & 98.713 \\
\hline 3 & 0.457 & 0.830 & 0.498 & 98.672 \\
\hline 4 & 0.630 & 0.975 & 0.393 & 98.631 \\
\hline 5 & 0.851 & 1.080 & 0.319 & 98.601 \\
\hline 6 & 1.135 & 1.151 & 0.266 & 98.583 \\
\hline 7 & 1.505 & 1.196 & 0.228 & 98.576 \\
\hline 8 & 1.988 & 1.221 & 0.202 & 98.577 \\
\hline 9 & 2.622 & 1.233 & 0.184 & 98.583 \\
\hline 10 & 3.453 & 1.238 & 0.171 & 98.592 \\
\hline
\end{tabular}

Source: World Bank and FAO. Software: EViews SV 11. Note: S.E. refers to standard error

More so, the study conducted the impulse response analysis (IRF) to show how the dynamic system respond to external shocks. The IRF is depicted by Graph 3. From Graph 3, it can be observed that the dynamic system is said to be stable if any shock declined to zero; otherwise it was unstable if it leads to an explosive time path. 


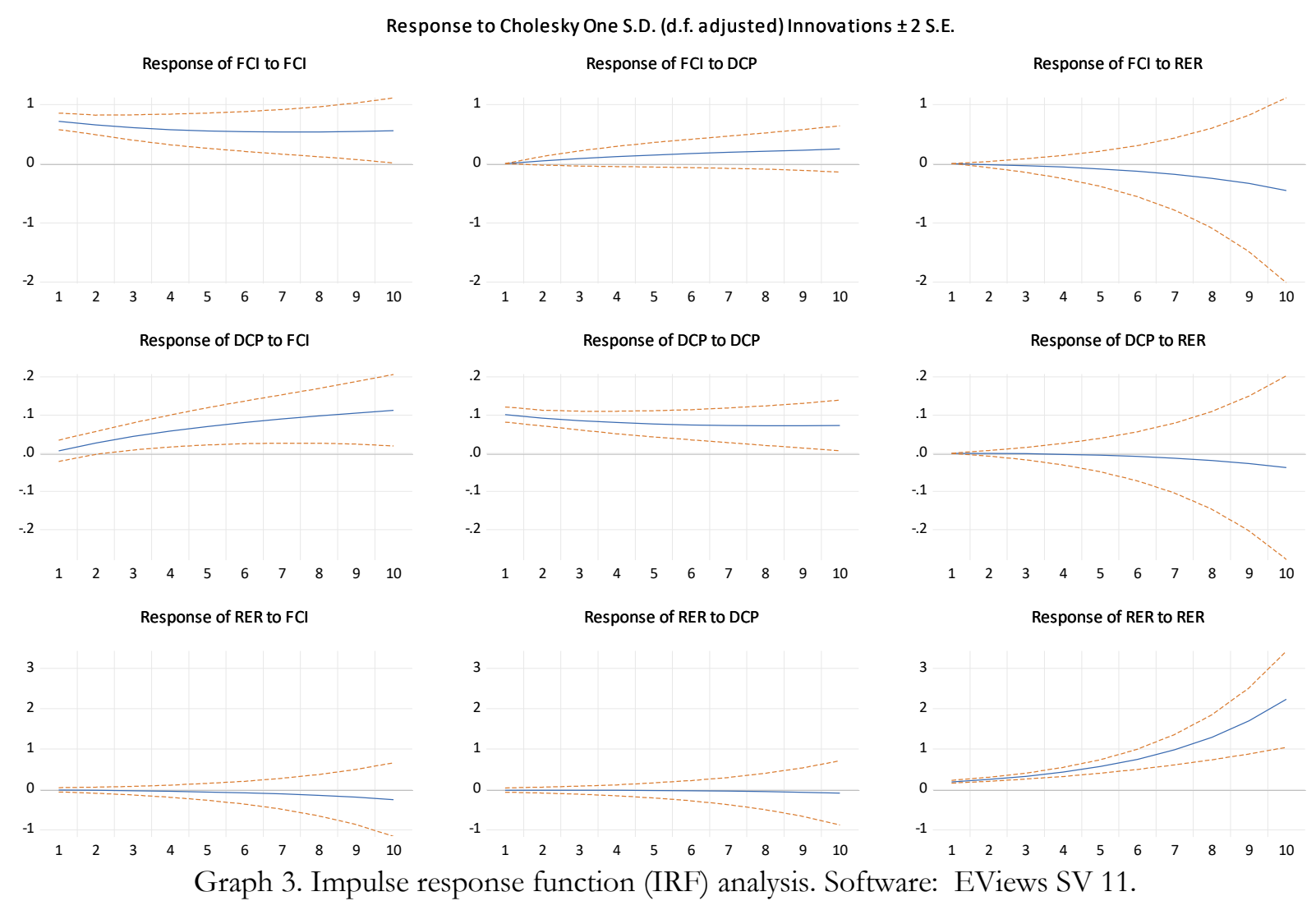

\section{CONCLUSION}

The main objective of the study was to establish the existence of a joint causal relationship between frozen chicken import, domestic chicken production, and real exchange rate in Ghana using frequency domain causality test, granger causality test, unrestricted VAR framework, and annual data from 1964 to 2016. The empirical results showed a strong positive correlation between frozen chicken import and domestic chicken production, and between domestic chicken production and real exchange rate in Ghana. The pairwise granger causality test indicate a bidirectional causal relationship between frozen chicken import and domestic chicken production and a unidirectional causality running from domestic chicken production and frozen chicken import to real exchange rate.

Also, the frequency-domain causality test shows a unidirectional causality running from domestic chicken production to frozen chicken import and from frozen chicken import to real exchange rate, however, a bidirectional causality was found between domestic chicken production and real exchange rate in the short run. In addition, in the intermediate and long run, the frequency-domain causality test showed a unidirectional causality from domestic chicken production to frozen chicken import and from frozen chicken import to real exchange rate. The results suggest that domestic chicken production affects real exchange rate via frozen chicken import.

The VDC and IRF results indicate that none of the three variables stand entirely as exogenous however, the degree of the endogeneity is contingent on the type of variable concerned. The VDC results also show that frozen chicken import largely determines domestic chicken production while real exchange rate largely influences frozen chicken import in Ghana. That is, overtime, as frozen chicken import and real exchange rate increase, domestic chicken production also decrease. 
The outcome of this paper has important implications for global food policy and trade policy. Thus, the Ministry of Food and Agriculture could rely on these findings to design policies that will boost chicken production and hence stabilize the exchange rate in Ghana. The study suggests that increase in domestic chicken production could lead to lower frozen chicken import and hence stabilize the exchange rate in Ghana. For example, "the rearing for food and job" policy the ministry has currently adopted to increase meat production in Ghana can be supported by some trade barriers measures to decrease frozen chicken import. Thus, the government can increase subsidies on chicken production so as to decrease frozen chicken import and hence stabilize the real exchange rate in Ghana. Furthermore, since feed cost largely drive chicken production in Ghana, the Government can encourage domestic production of maize which is the major ingredient of poultry feed in Ghana. Other African countries such as Angola, South Africa, Congo, Gabon, The Gambia, Libya, Sierra Leone, Benin, Equatorial Guinea, Namibia, and Liberia among others import significant amount of frozen chicken from the US and the EU, so future researchers can extend the current study to encompass these countries.

\section{REFERENCES}

Andam, K. S., Johnson, M. E., Ragasa, C., Kufoalor, D. S., \& Das Gupta, S. (2017). A chicken and maize situation: the poultry feed sector in Ghana (Vol. 1601). Intl Food Policy Res Inst.

Amanor-Boadu, V., Nti, F. K., \& Ross, K. (2016). Structure of Ghana's chicken industry in 2015. METSS. October.

Aning, K. G. (2006). The structure and importance of the commercial and village-based poultry. Poultry Sector Country Review: Ghana, 20-28.

Al-Hassan, R. M., Larvoe, N., \& Adaku, A. A. (2014). Hedonic price analysis of dressed chicken in Ghana. International Journal of Business and Social Science, 5(12), 215-223.

Banson, K. E., Muthusamy, G., \& Kondo, E. (2015). The import substituted poultry industry; evidence from Ghana.

Breitung, J., \& Candelon, B. (2006). Testing for short-and long-run causality: A frequency-domain approach. Journal of econometrics, 132(2), 363-378.

Ciner, C. (2011). Eurocurrency interest rate linkages: A frequency domain analysis. International Review of Economics \& Finance, 20(4), 498-505.

Donkor, J., Sarpong, A., Kankam-Kwarteng, C., \& Duah, F. A. (2013). Consumer choice analysis of imported and locally produced chicken products: Evidence from Ghana. European Journal of Business and Management, 5(32), 7483.

Food and Agricultural Organization (FAO) (2017). Food and Agricultural data. Retrieved from http://www.fao.org/faostat/en/\#data on 02/18/2017

Geweke, J. (1982). Measurement of linear dependence and feedback between multiple time series. Journal of the American statistical association, 77(378), 304-313.

Ghana Business News (2017). Ghana import 135,000 tons of Chicken from Europe in 2017. Retried from https://www.ghanabusinessnews.com/2018/03/23/ghana- import-135000-tons-of-chicken-from-europe-in2017 / on $03 / 13 / 2020$

Ghana Agricultural and Rural Development Journalists Association (GARDJA) (2015). Ghana's frozen chicken import hits US $\$ 300$ million annually. Retrieved from https://www.gardja.org/ghanas-frozen-chicken-import-hits-us300-million-annually/ on 03/21/2020

Gujarati, D. (2004). Basic Econometrics Fourth (4th) Edition. Magraw Hill Inc, New York.

Granger, C. W. (1969). Investigating causal relations by econometric models and cross-spectral methods. Econometrica: journal of the Econometric Society, 424-438.

Granger, C. J. (1986). Developments in the study of cointegrated economic variables. Oxford Bulletin of economics and statistics, 48(3), 213-228.

Hosoya, Y. (1991). The decomposition and measurement of the interdependency between second-order stationary processes. Probability theory and related fields, 88(4), 429-444. 
Kusi, L. Y., Agbeblewu, S., Anim, I. K., \& Nyarku, K. M. (2015). The challenges and prospects of the commercial poultry industry in Ghana: a synthesis of literature. International Journal of Management Sciences, 5(6), 476-489.

Ministry of Food and Agriculture (2019). Revamping the Poultry Sector in Ghana. Retrieved from http://mofa.gov.gh/site/publications/research-reports/54-revamping-the-poultry-sector-in-ghana 03/19/2020.

Sims, C. A. (1972). Money, income, and causality. The American economic review, 62(4), 540-552.

Stock, J. H., \& Watson, M. W. (2001). Vector autoregressions. Journal of Economic perspectives, 15(4), 101-115.

Sumberg, J., Awo, M., \& Kwadzo, G. T. M. (2017). Poultry and policy in Ghana: Lessons from the periphery of an agricultural policy system. Development Policy Review, 35(3), 419-438.

Tastan, H. (2015). Testing for spectral Granger causality. The Stata Journal, 15(4), 1157-1166.

The Business Day Ghana (2015). Ghana’s frozen chicken import to rise to \$198 million in 2016. Retrieved from https://www.newsghana.com.gh/ghanas-chicken- import-to-rise-to-198m-in-2016/ on 02/13/2017

The Poultry Site (2016). Nigeria's Ban on Poultry Imports-Important Lessons for Ghana https:/ thepoultrysite.com/news/2016/06/nigerias-ban-on-poultry-imports-important-lessons-for-ghana

Woolverton, A. E., \& Frimpong, S. (2013). Consumer demand for domestic and imported broiler meat in urban Ghana: bringing non-price effects into the equation. British Journal of Marketing Studies, 1(3), 16-31.

USDA, FAS (2008). Ghana Poultry and Products Annual 2008. Retrieved from https://apps.fas.usda.gov/gainfiles/200808/146295648.pdf on 03/21/2020

USDA, FAS (2017). Ghana Poultry and Products Annual 2017. Retrieved from https://apps.fas.usda.gov/newgainapi/api/report/downloadreportbyfilename?filename $=2017 \% 20 \mathrm{ghana} \% 20$ poultry\%20report\%20annual\%20_accra_ghana_5-23-2017.pdf on 03/21/2020

USDA, ERS (2020). Livestock and Meat International Trade Data. Retrieved from https://www.ers.usda.gov/dataproducts/livestock-and-meat-international-trade-data/ on 04/01/2020. 


\section{APPENDICES}

\section{Appendix A}

Table 12

The VAR Results

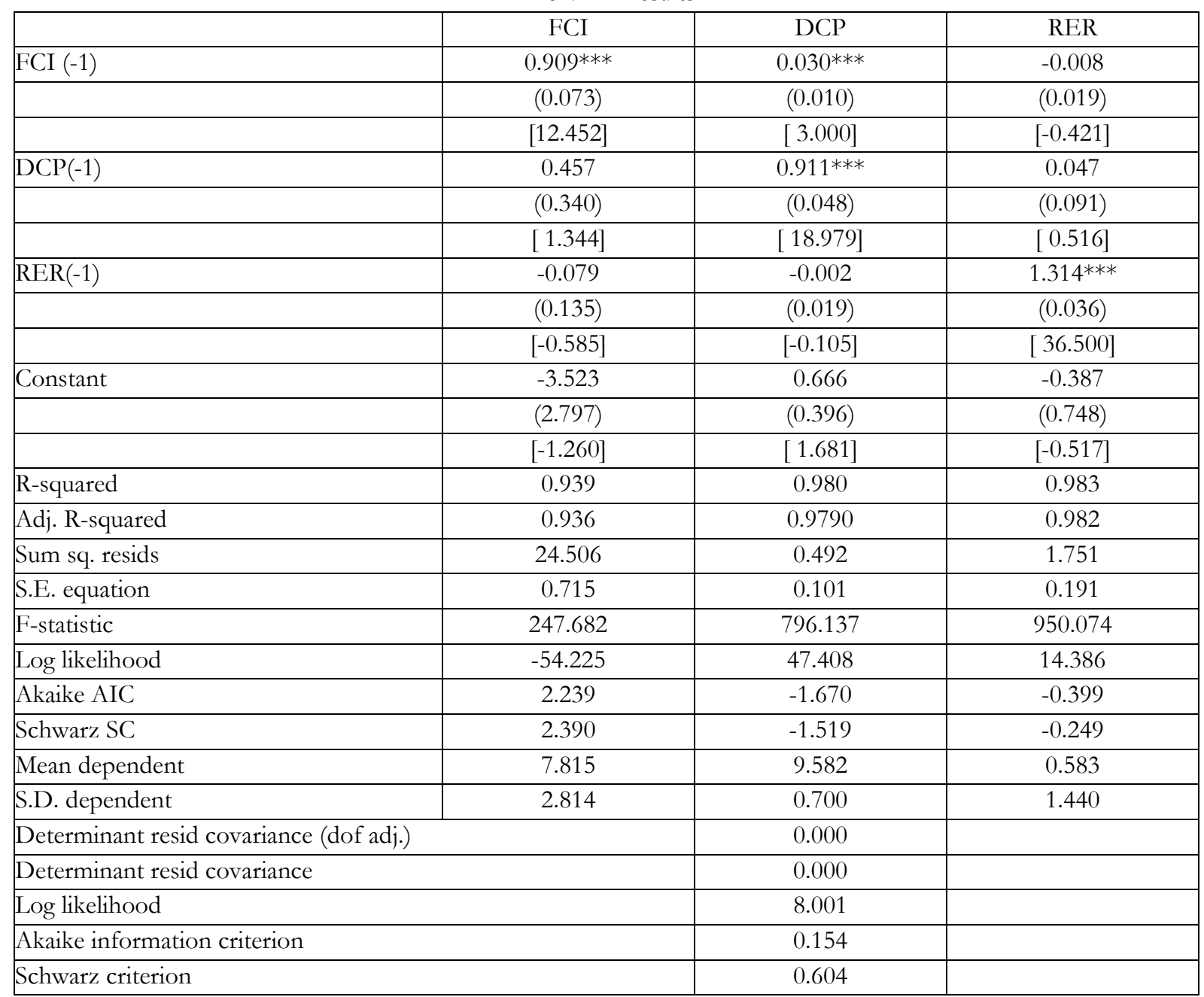

Note: $*, * *, * * *$ indicates $1 \%, 5 \%$, and $10 \%$ significance level respectively,

values in bracket are standard errors, values in parenthesis are t-statistic. Source: World Bank and FAO,

Software: EViews SV 11. 


\section{Appendix B}
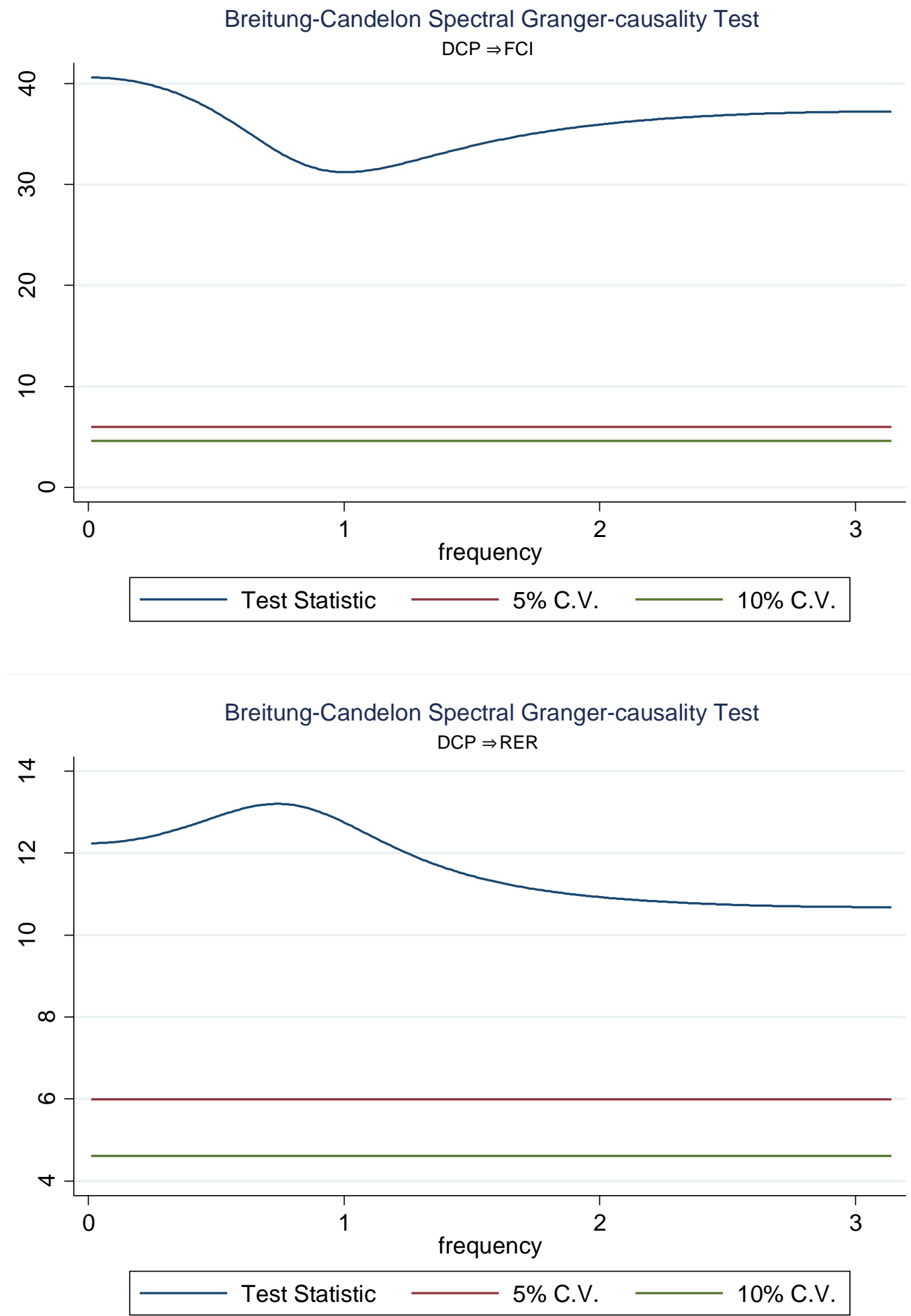


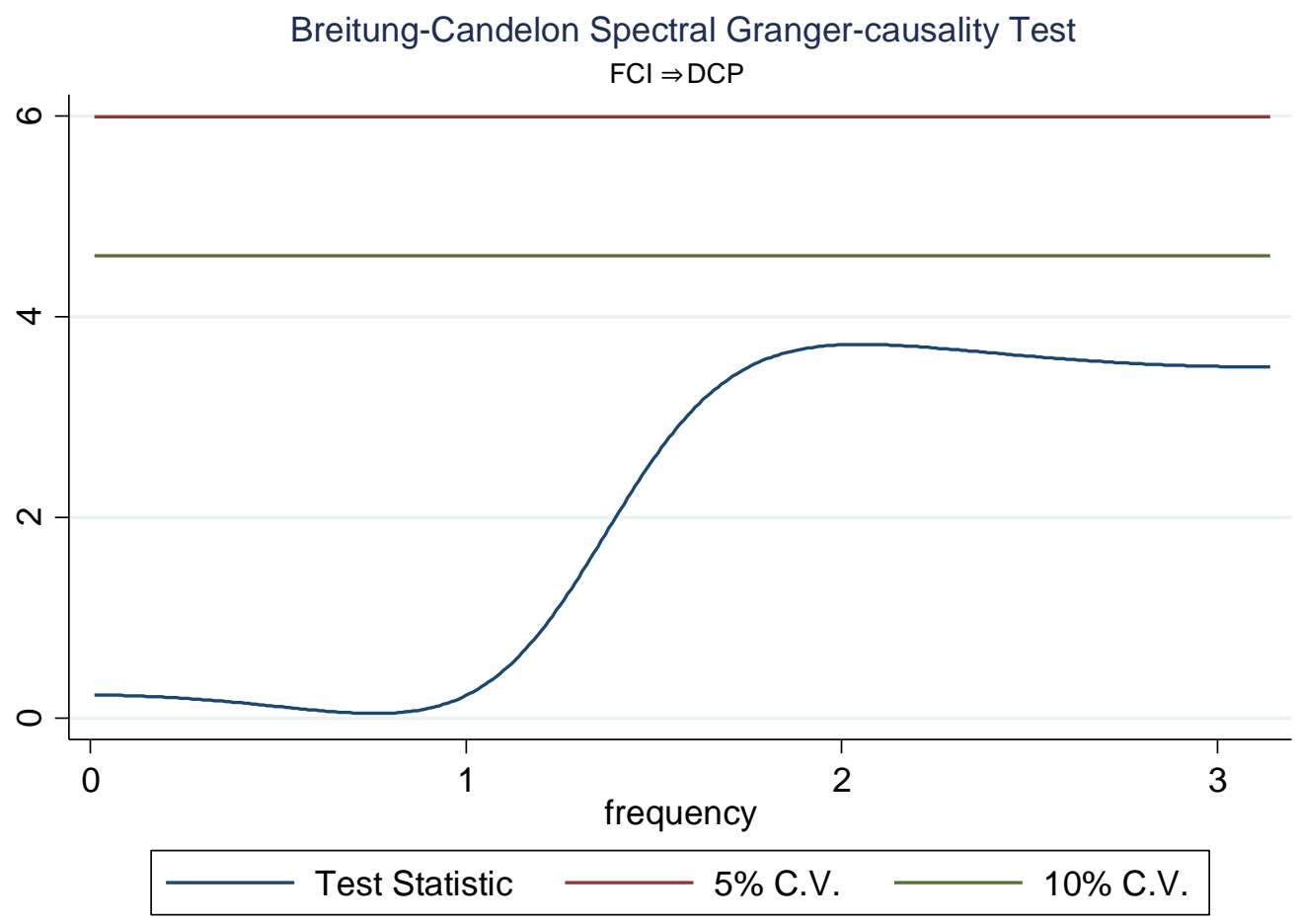

Breitung-Candelon Spectral Granger-causality Test

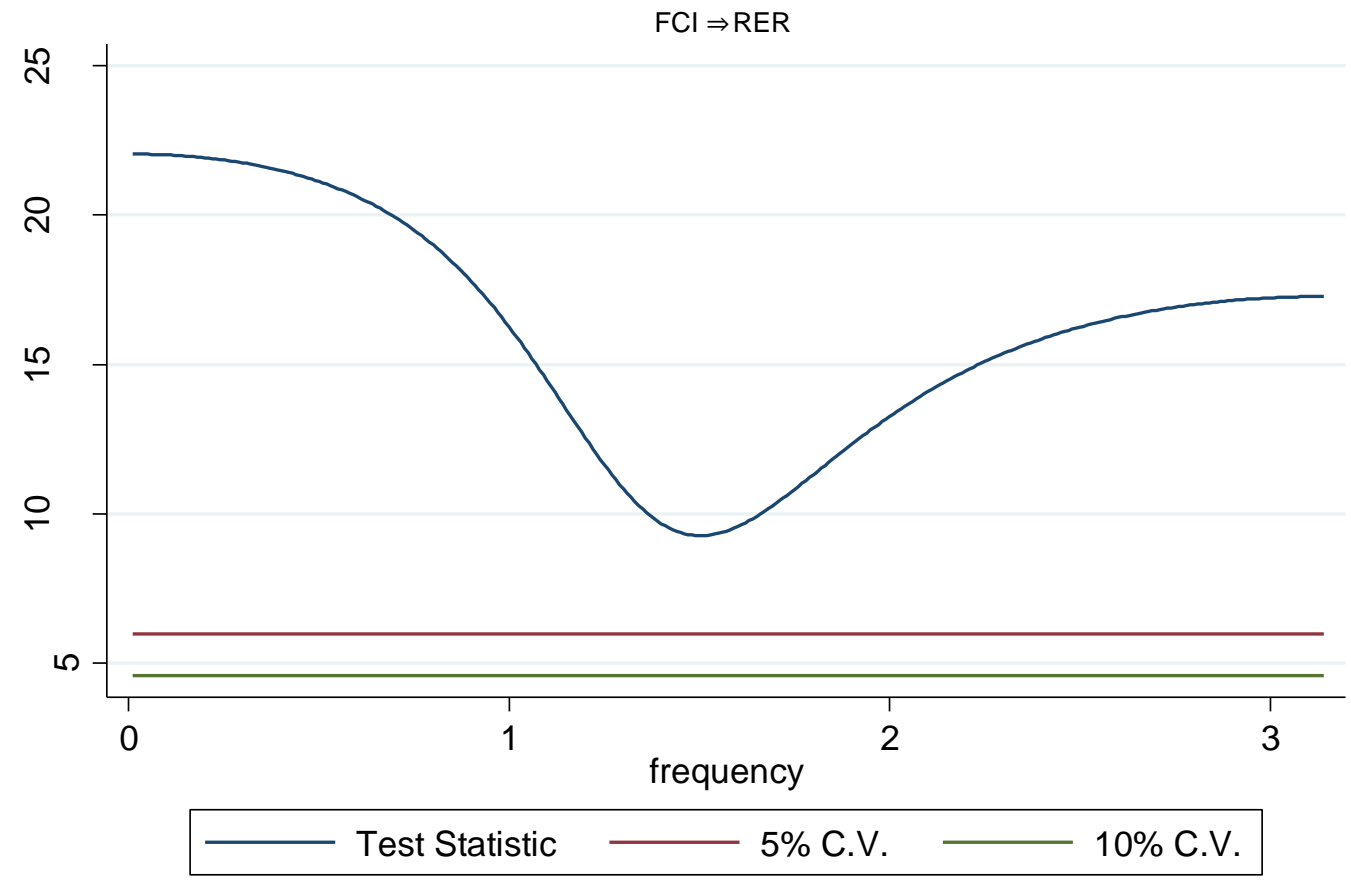


Breitung-Candelon Spectral Granger-causality Test $\mathrm{RER} \Rightarrow \mathrm{DCP}$

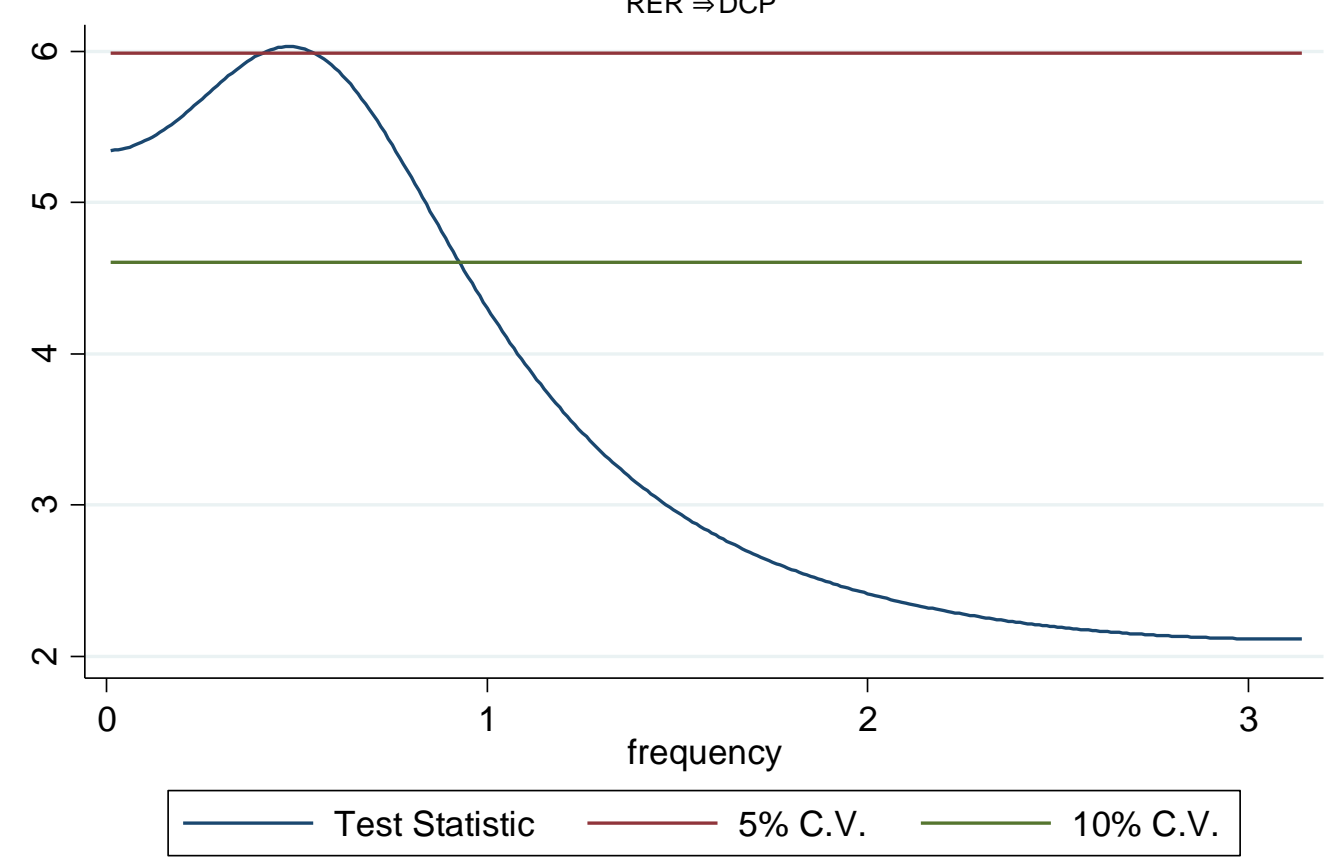

Breitung-Candelon Spectral Granger-causality Test $\mathrm{RER} \Rightarrow \mathrm{FCl}$

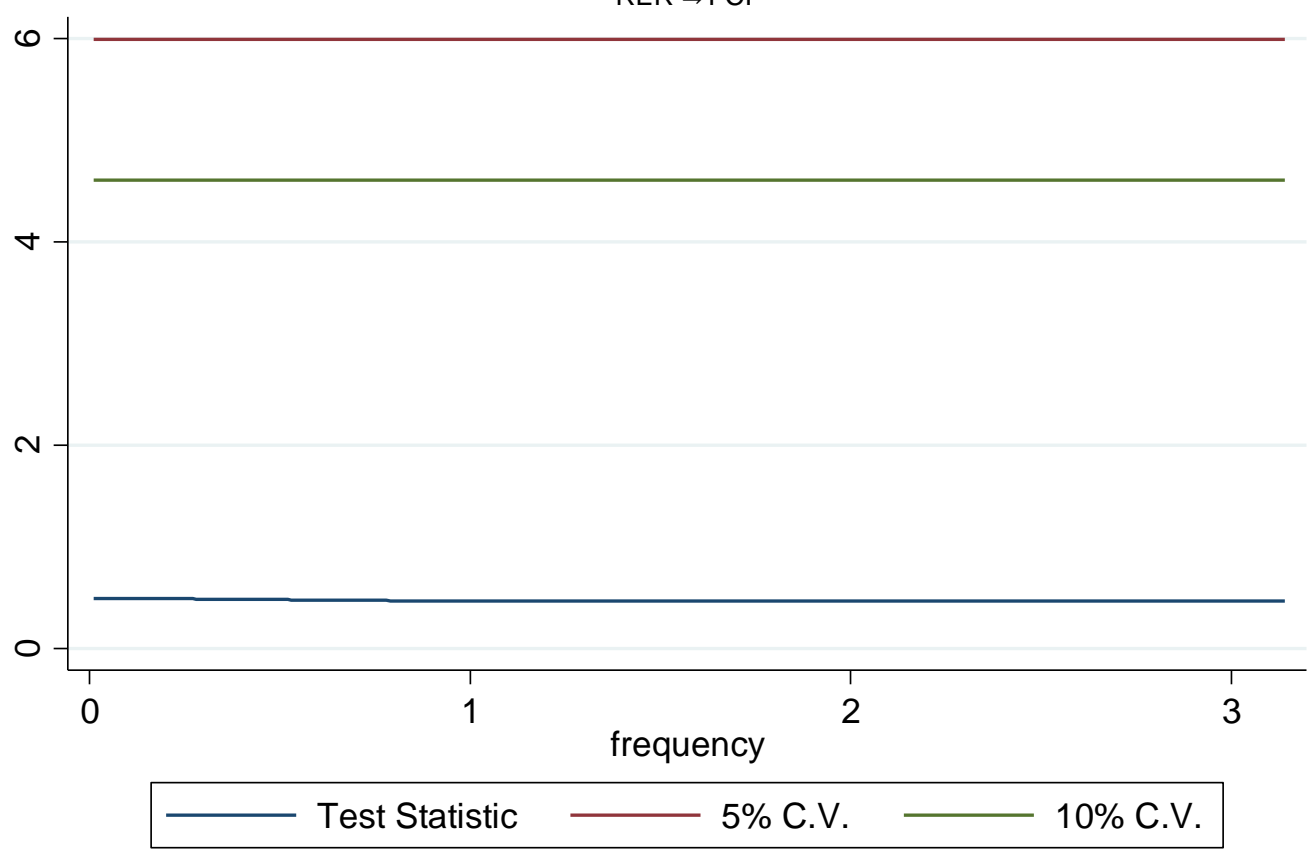

